\title{
In Vitro Assessment of Antibacterial Activity and Cytocompatibility of Quercetin-Containing PLGA Nanofibrous Scaffolds for Tissue Engineering
}

\author{
Zhi-Cai Xing, ${ }^{1}$ Wan Meng, ${ }^{2}$ Jiang Yuan, ${ }^{3}$ Sungmo Moon, ${ }^{4}$ Yongsoo Jeong, ${ }^{4}$ and Inn-Kyu Kang1 \\ ${ }^{1}$ Department of Polymer Science and Engineering, Kyungpook National University, Daegu 702-701, Republic of Korea \\ ${ }^{2}$ Department of Chemical Engineering, Yanbian University, Yanji 133002, China \\ ${ }^{3}$ Jiangsu Key laboratory of Biofunctional Materials, College of Chemistry and Environmental Science, Nanjing Normal University, \\ Nanjing 210097, China \\ ${ }^{4}$ Materials Processing Division, Korea Institute of Materials Science, Changwon 641-010, Republic of Korea \\ Correspondence should be addressed to Inn-Kyu Kang, ikkang@knu.ac.kr
}

Received 7 June 2011; Revised 21 November 2011; Accepted 21 November 2011

Academic Editor: Donglu Shi

Copyright ( 12012 Zhi-Cai Xing et al. This is an open access article distributed under the Creative Commons Attribution License, which permits unrestricted use, distribution, and reproduction in any medium, provided the original work is properly cited.

Flavonoids, such as quercetin, have been reported to exhibit a wide range of biological activities related to their antioxidant capacity. The aim of this study was to investigate the protective effect of quercetin on cell adhesion, and the viability and proliferation of $\mathrm{KB}$ epithelial cells. Quercetin- (1,5 wt \%)-containing poly (1-lactide-co-glycolide) (PLGA) nanofibrous scaffolds (PLGA/Q 1, PLGA/Q 5) were prepared by electrospinning technique and their antibacterial properties were examined. Two types of bacteria strains, Staphylococcus aureus (SA) and Klebsiella pneumoniae (KP), were used to evaluate the antibacterial properties of the scaffolds. The results showed that the quercetin-containing PLGA nanofibrous scaffolds exhibited significant antibacterial effects against the two bacterial strains. KB epithelial cells were also used to evaluate the cytocompatibility of the scaffolds. From the results, it was found that the PLGA nanofibrous scaffolds with $1 \mathrm{wt} \%$ of quercetin had good cell compatibility. It is considered that the PLGA nanofibrous scaffolds with $1 \mathrm{wt} \%$ quercetin have potential to be used in tissue engineering.

\section{Introduction}

Dietary antioxidants, including polyphenolic compounds, are considered beneficial because of their potential protective role in the pathogenesis of multiple diseases associated to oxidative stress such as cancer, coronary heart disease, and atherosclerosis [1]. Flavonoids comprise a large group of naturally occurring low molecular weight polyphenolic compounds that are present in all plants [2]. Flavonoids, especially flavonols such as quercetin, have been reported to exhibit a wide range of biological activities [3], including anticarcinogenic, anti-inflammatory, and antiviral actions.

The flavonoid used in this study, quercetin, is one of the most abundant flavonol-type flavonoids present in several components of a human's diet such as vegetables, fruit, tea, and wine [3] with a well-characterized antioxidant activity in vitro $[4,5]$. Quercetin exhibits a wide range of physiological and pharmacological activities relevant to human health, such as anticarcinogenic, anti-inflammatory, and antiviral actions $[6,7]$. Many of these effects are supposed to be related to its antioxidant property. The mode of action for quercetin is scavenging free radicals through chelating divalent cations which inhibits some enzymes and protect the DNA damage. Therefore, quercetin may be considered as an effective attenuating factor for preventing various disorders caused by environmental contaminants [8-10].

Electrospun nanofiber matrices have been widely used for tissue regeneration of blood vessels $[11,12]$, skin $[13,14]$, cartilage $[15,16]$, bone $[17,18]$, and nerve [19]. Poly (1-lactide-co-glycolide) (PLGA) has been approved for several biomedical applications in humans and widely used as a scaffold material in tissue engineering [20-23]. PLGA nanofibers have been shown to promote the adhesion of interstitial and endothelial cells [24], the growth of fetal pulmonary cells 


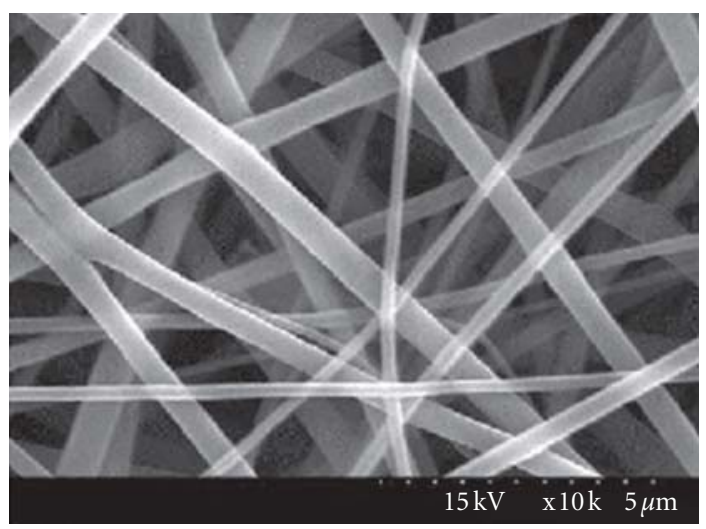

(a)

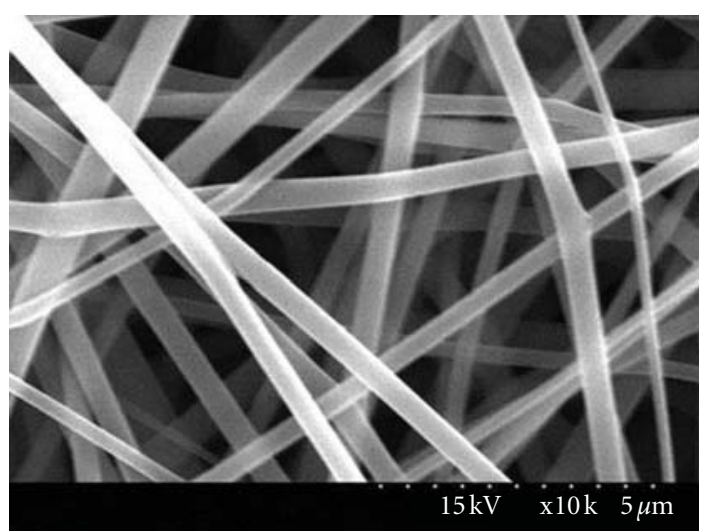

(b)

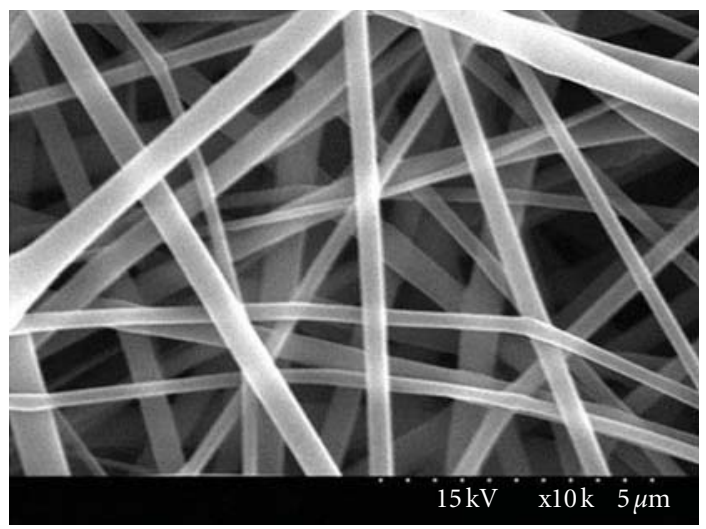

(c)

Figure 1: SEM micrographs of electrospun (a) PLGA, (b) PLGA/Q 1, and (c) PLGA/Q 5 nanofibrous scaffolds.

[25] and porcine chondrocytes [26]. Our previous study [27] showed that the silver-containing PLGA nanofibrous scaffolds inhibited the proliferation of Staphylococcus aureus (SA) and Klebsiella pneumoniae (KP) bacteria, without exhibiting any in vitro cell cytotoxicity. However, to date, no report has yet been published showing the antibacterial activity and cytotoxicity of quercetin-containing PLGA nanofibrous scaffolds using the electrospinning technique.

In this study, the antibacterial and biological properties of the quercetin-containing PLGA nanofibrous scaffolds

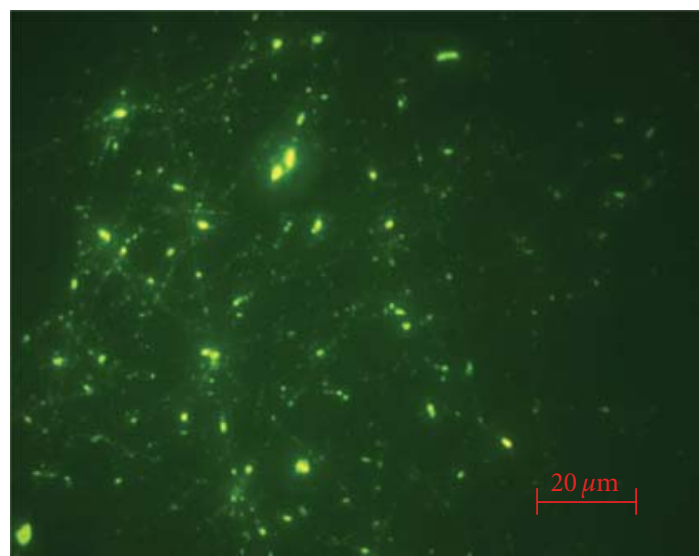

FIgure 2: The fluorescence image of PLGA/Q 5 nanofibrous scaffolds.

were studied. Two types of bacterial strains, Staphylococcus aureus (SA) and Klebsiella pneumoniae (KP), were chosen to evaluate the antibacterial activity of the quercetin-containing PLGA nanofibrous scaffolds. Furthermore, in vitro cytotoxicity was examined by conducting tests on the scaffolds as well.

\section{Materials and Methods}

2.1. Preparation of Polymer Solution. Poly (1-lactide-co-glycolide) (PLGA, polymer composition: 79:21 85:15 molar ratio, Aldrich Chemical Co., USA) was dissolved in 1,1,1, 3,3,3,-hexafluoro-2-propanol (HFIP) with a concentration of $4 \mathrm{wt} \%$ and the solution was stirred overnight at room temperature to ensure complete dissolution. Then, certain amounts of quercetin dihydrate (Q, Sigma-Aldrich, USA) $(1,5 \mathrm{wt} \%)$ were mixed with the PLGA solution and stirred by magnetic stirrer for $24 \mathrm{~h}$ to obtain the PLGA/Q solution. The quercetin-containing PLGA nanofibrous scaffolds were named PLGA/Q 1 and PLGA/Q 5, respectively.

2.2. Electrospinning. The electrospinning experiments were done at room temperature and the apparatus for the electrospinning was assembled based on a study done by Lee et al. [28]. The polymer solution was placed into a $10 \mathrm{~mL}$ glass syringe fitted with a needle $(20 \mathrm{G})$. A clamp connected to a high voltage power supply that could supply a positive voltage from 0 to $50 \mathrm{kV}$ was attached to the needle. A piece of aluminum foil was placed at a distance of $15 \mathrm{~cm}$ away from the needle tip. The polymer jets generated from the needle by high voltage flew to the collector and formed a nanofiber mesh. The polymer solutions were electrospun with a fixed mass flow rate of $1.0 \mathrm{~mL} / \mathrm{h}$ and a voltage of $10 \mathrm{kV}$. Finally, the electrospun samples were dried overnight at $40^{\circ} \mathrm{C}$ to remove the solvent. The morphologies of the electrospun nanofibers were observed by field emission scanning electron microscope (FE-SEM S-4300, Hitachi, Japan) and the fluorescence images of the electrospun nanofibers (PLGA/Q 5) were obtained using a fluorescence microscope (Carl zeiss, Germany). 


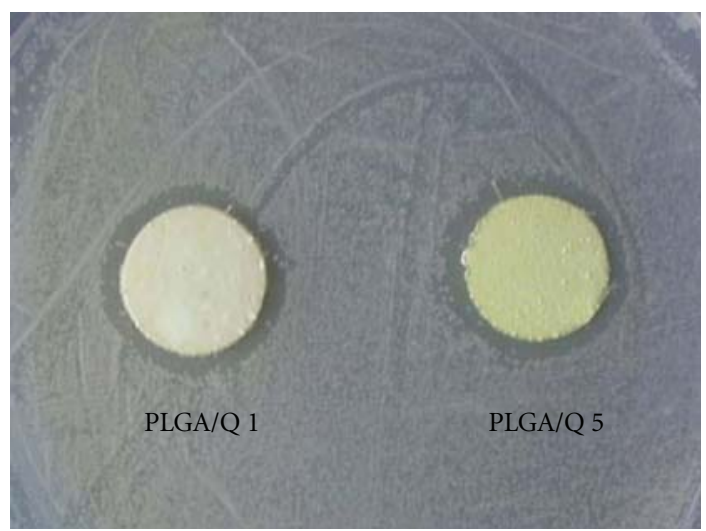

(a)

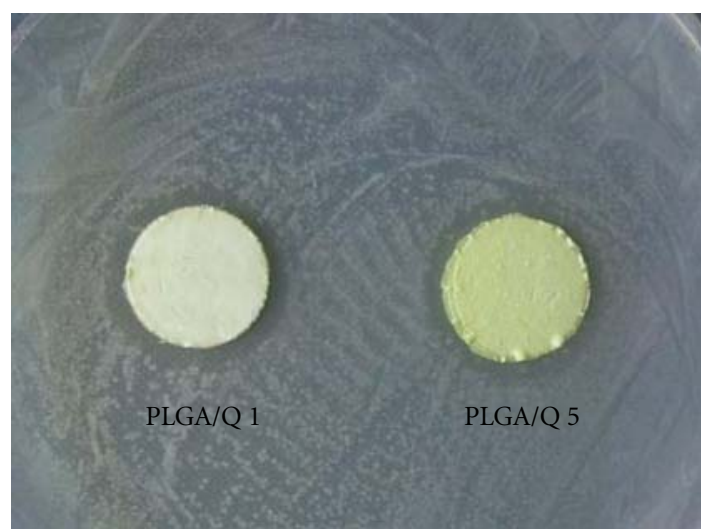

(b)

FIGURE 3: Effect of the quercetin on the formation of inhibition zones: (a) Staphylococcus aures and (b) Klebsiella pneumonia.

2.3. Antibacterial Assessment. For the zone of inhibition screening test for antibacterial activity, Staphylococcus aureus (SA 6538) and Klebsiella pneumoniae (KP 4352) were cultivated in a nutrient broth for $24 \mathrm{~h}$ in a $\mathrm{CO}_{2}$ incubator. Afterwards, diluted bacteria suspensions collected from each vial were spread onto nutrient broth agar plate. After that, the PLGA/Q 1 and PLGA/Q 5 nanofibrous mats were each placed onto a lawn Staphylococcus aureus and Klebsiella pneumoniae on the agar plates and incubated overnight at $37^{\circ} \mathrm{C}$. The zone of inhibition formed around the nanofibrous mats was observed against the two microorganisms.

2.4. Quercetin Release. The quercetin release test was done by immersing the PLGA/Q 5 nanofibrous scaffold $\left(4 \times 4 \mathrm{~cm}^{2}\right.$, $0.02 \mathrm{~g})$ into distilled water $(5 \mathrm{~mL}, \mathrm{pH} 7.2)$ for different periods of time. The amount of quercetin released from the sample was measured by UV-visible spectra (JASCO V-650).

2.5. Cell Attachment. In order to examine the interaction of the nanofibrous scaffolds with $\mathrm{KB}$ epithelial cells, circular nanofibrous scaffolds were fitted in a 24-well culture dish and subsequently immersed in a DMEM medium containing $10 \%$ fetal bovine serum (FBS) (Gibco, Japan) and 1\% penicillin G-streptomycin (Gibco, Japan). To the scaffolds, $1 \mathrm{~mL}$ of the cell solution $\left(3 \times 10^{4}\right.$ cells $\left./ \mathrm{cm}^{2}\right)$ was added and incubated in a humidified atmosphere of $5 \% \mathrm{CO}_{2}$ at $37^{\circ} \mathrm{C}$ for $4 \mathrm{~h}$. After incubation, the supernatant was removed, washed twice with PBS, and fixed in a $2.5 \%$ glutaraldehyde aqueous solution for $20 \mathrm{~min}$. The sample sheet was then dehydrated, dried in a critical point drier, and finally sputter-coated with gold. The surface morphology of the samples was then observed with FE-SEM.

2.6. Cell Proliferation. The proliferation of $\mathrm{KB}$ epithelial cells was determined using a colorimetric immunoassay, enzymelinked immunosorbent assay (ELISA). The ELISA method was based on the measurement of 5-bromo-2-deoxyuridine (BrdU), which was incorporated during DNA synthesis. The ELISA was done according to the manufacturer's instructions (Roche Molecular Biochemicals).
2.7. Cell Viability. A standard live/dead assay [29] was used to image cell survival, adhesion, and spatial organization. KB epithelial cells were collected by centrifugation and then were incubated in calcein-AM ( $1 \mathrm{mM}$ in DMSO) and propidium iodide (PI, $1.5 \mathrm{mM}$ in $\mathrm{H}_{2} \mathrm{O}$ ) solution for $15 \mathrm{~min}$. Cells with compromised membranes exhibited red-fluorescence from the intercalation of the propidium iodide into the DNA double helix. Cells with intact cell membranes were able to use nonspecific cytosolic esterases to convert nonfluorescent calcein-AM into bright green-fluorescent calcein. Cells were observed under a fluorescence microscope using a band-pass filter (Nikon Eclipse E600-POL, Japan).

\section{Results and Discussion}

3.1. Surface and Morphology of Nanofibers. Figure 1 shows SEM images of the electrospun nanofibers from $4 \mathrm{wt} \%$ PLGA solutions with different amounts of quercetin $(0,1$, and $5 \mathrm{wt}$ $\%)$. It was observed that the diameter distribution of the PLGA nanofibers did not change when the quercetin was added to the PLGA solution (Figure 1). Figure 2 shows the fluorescence images of quercetin which randomly dispersed through the PLGA nanofibrous scaffold.

3.2. Antibacterial Activity. For the zone of inhibition screening test for the antibacterial activity, PLGA/Q 1 and PLGA/Q 5 nanofibrous scaffolds were placed onto a lawn of organisms on an agar plate and incubated for $24 \mathrm{~h}$. After incubation, antibacterial responses were observed in both test cases. The bactericidal activity displayed a good zone of inhibition, that is, the region in which the bacterial species were unable to propagate around the PLGA/Q fiber mats (Figure 3). In addition, the growth inhibition rate of the bacteria increased a little with an increase in quercetin content (Figure 3 ). This is attributed to trace amounts of quercetin released from the fiber, which attached to the bacteria and inhibited nucleic acid synthesis, cytoplasmic membrane function and energy metabolism [30].

The antibacterial activity of the scaffolds is based on the role of the quercetin that was embedded in the surface of the scaffold or released from the scaffold. Therefore, in this study, 


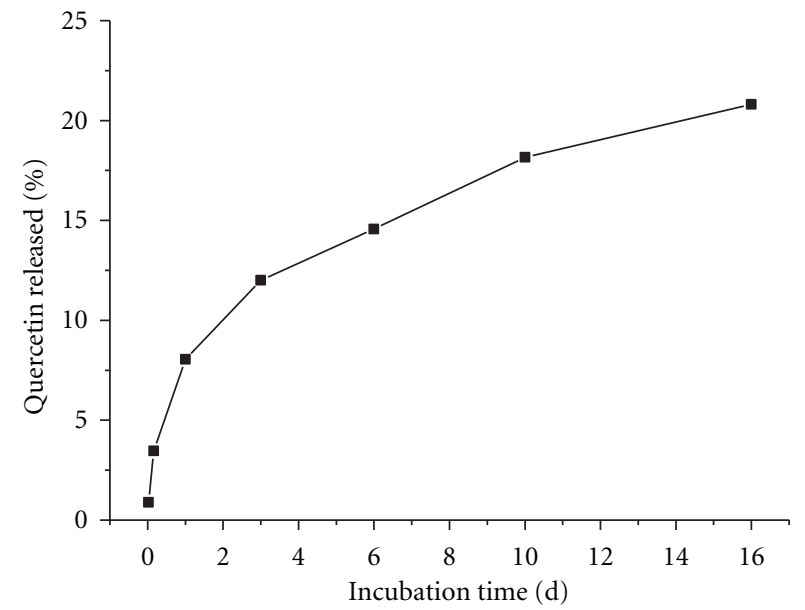

Figure 4: The percentage of quercetin released from PLGA/Q 5 nanofibrous scaffolds as a function of the immersion time.

the amount of quercetin released from the PLGA/Q 5 nanofibrous scaffold was calculated using UV-visible spectra. As shown in Figure 4, the percentage of released quercetin gradually increased with an increase in incubation time, and it reached $20.8 \%$ after 16 days of incubation. Rapid release of quercetin from PLGA/Q 5 is probably due to the high surface area of the nanofibrous scaffold. The released quercetin from the nanofibrous scaffold showed a high inhibitory effect on the growth of bacteria and killed the microorganisms, as seen in Figure 3.

3.3. In Vitro Cell Compatibility. As seen in Figure 5, KB epithelial cells were attached on the surface of three different scaffolds, and the number of cells attached on the surface of the PLGA nanofibrous scaffolds (Figure 5(a)) was not much different from those the quercetin-containing PLGA nanofibers (Figures 5(b) and 5(c)). The cells formed monolayers on the surface of the PLGA and PLGA/Q 1 nanofibrous scaffolds (Figures 6(a) and 6(b)) after 3 days of incubation. However, the monolayers were partially observed when the cells were cultured on the surface of the PLGA/Q 5 nanofibrous scaffolds (Figure 6(c)). Comparable results for differences in proliferation behavior, expressed as the amount of newly synthesized DNA, are shown in Figure 7. The cell proliferation on the quercetin-containing PLGA nanofibrous scaffolds (PLGA/Q 5) was significantly lower $(P<0.05)$ than that on the PLGA nanofibrous scaffolds (Figure 7) due to the antioxidant property of quercetin. The viability of cells cultured for 7 days on the nanofibrous scaffolds was observed by using the live/dead assay and the results are shown in Figure 8. The fluorescence colors of cells cultured on the PLGA and PLGA/Q 1 were green, indicating good viability of the cells. However, a few dead cells were found in the case of the PLGA/Q 5 nanofibrous scaffolds, which emitted a red fluorescence.

Quercetin has been reported to be a potent inhibitor of lipoxygenase (LOX) and cyclooxygenase (COX) activities, sodium-potassium adenosine triphosphatase (Na-KATPase), protein kinase $\mathrm{C}$ (PKC), and various tyrosine kinases [31]. Through one or more of the above biochemical

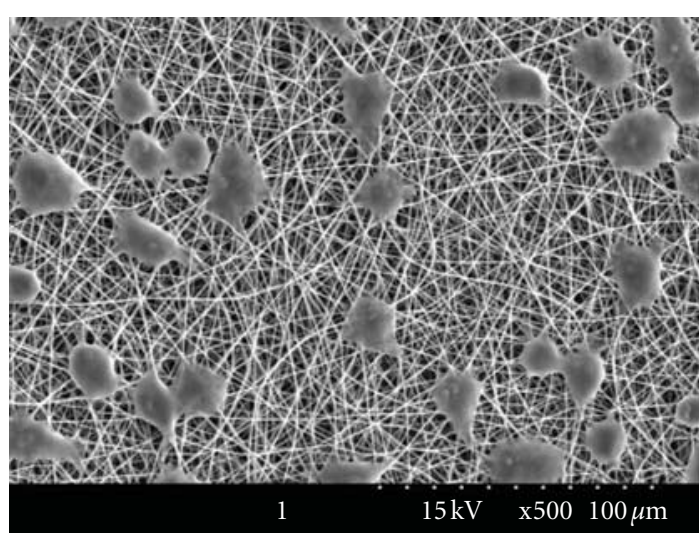

(a)

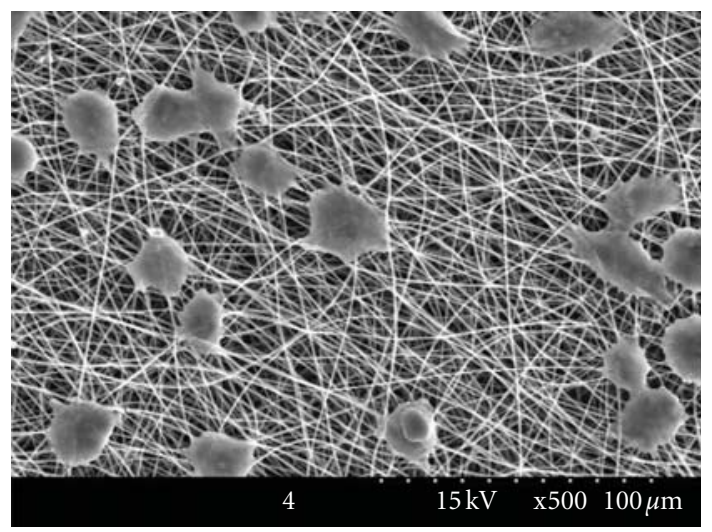

(b)

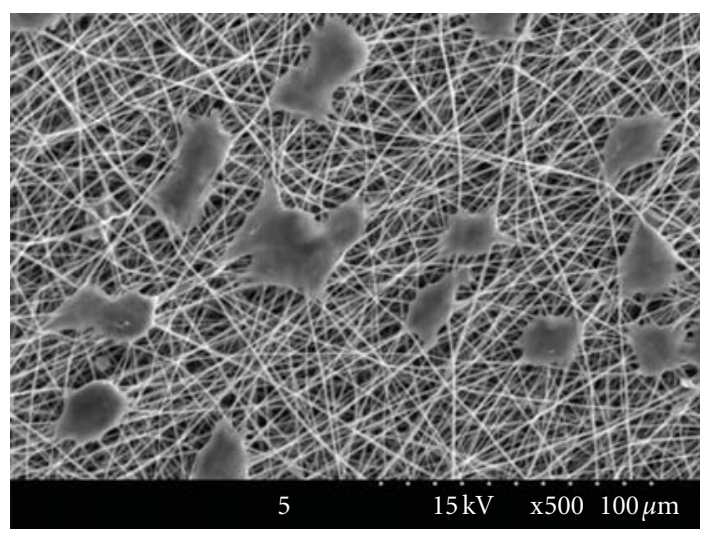

(c)

FigURE 5: SEM images of KB epithelial cells cultured for $4 \mathrm{~h}$ on (a) PLGA, (b) PLGA/Q 1, and (c) PLGA/Q 5 nanofibrous scaffolds.

mechanisms, quercetin has been reported to protect against both chemically induced and spontaneously formed tumors in animals $[31,32]$ and arrest cell proliferation in a variety of transformed cell lines in culture [32-36]. Alía et al. [5] concluded that doses of quercetin significantly decreased HepG2 cell proliferation, which has been previously reported for other cancer cells in vitro, such as human adenocarcinoma [37], human promyelocytic leukemia [38, 39], human colon cancer $[33,34,40]$, and murine hepatoma [41]. Still other investigators have found both preoxidant and antioxidant 


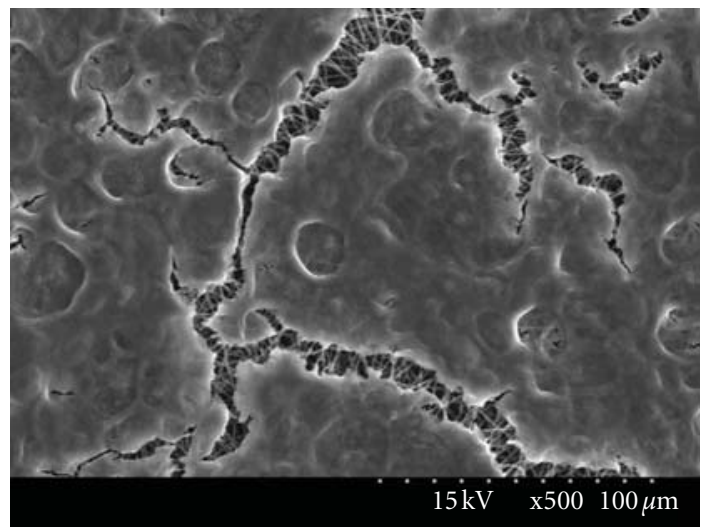

(a)

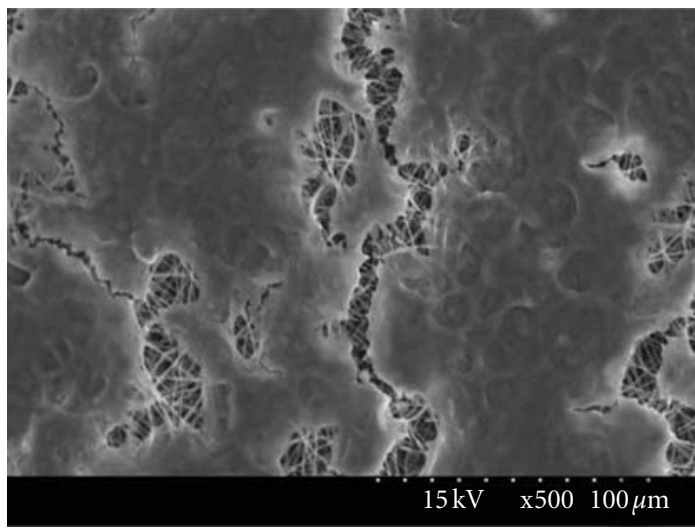

(b)

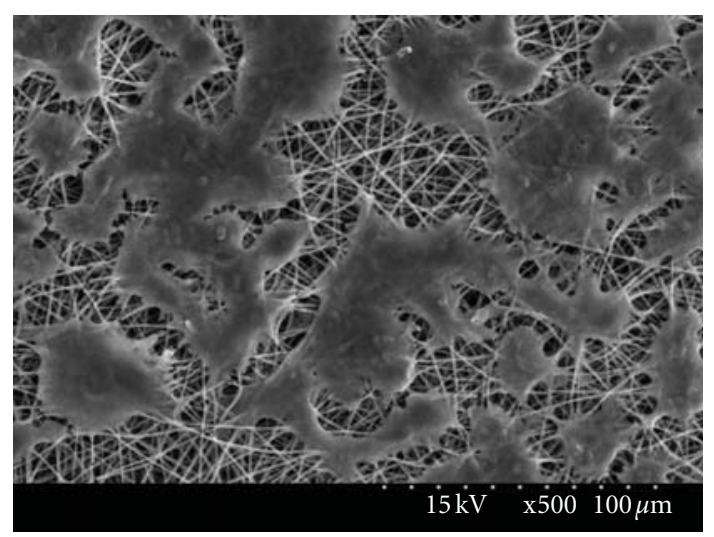

(c)

Figure 6: Morphology of KB epithelial cells incubated for 3 days on (a) PLGA, (b) PLGA/Q 1, and (c) PLGA/Q 5 nanofibrous scaffolds.

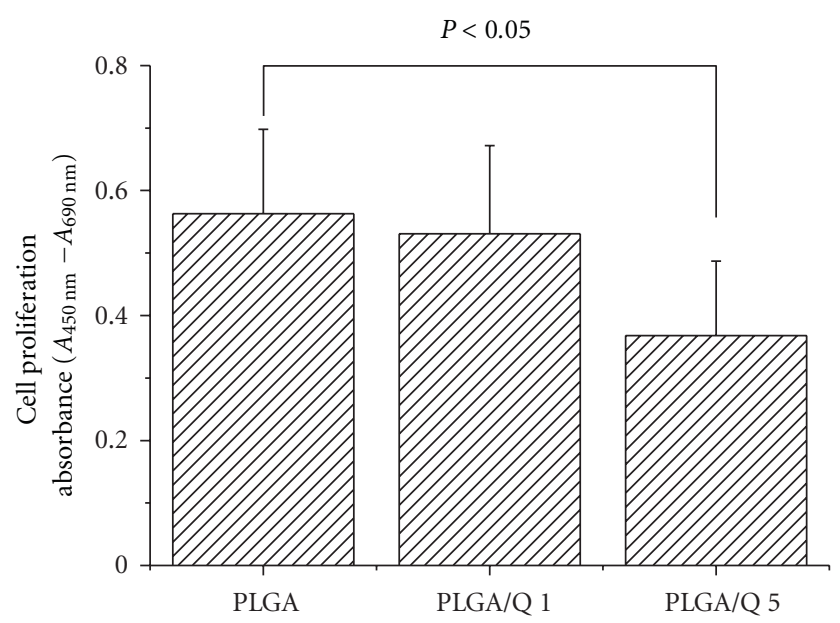

Figure 7: Proliferation of KB epithelial cells cultured for 3 days. Data are expressed as the means $\pm \mathrm{SD}(n=6)$ for the specific absorbance.

effects of quercetin depending on the concentrations used for experimentation [42]. In this study, the results showed that the quercetin-containing PLGA nanofibrous scaffolds affected the in vitro growth of the KB epithelial cells. Interestingly, the inhibitory effect of PLGA/Q 1 on the growth of $\mathrm{KB}$ epithelial cells was significantly low, indicating a lower activity or accessibility to the cultured cells. However, PLGA/Q 5 significantly reduced the proliferation of KB epithelial cells (Figure 7) due to the cytotoxic effect of the quercetin.

\section{Conclusions}

Quercetin-containing PLGA nanofibers were successfully prepared using an electrospinning technique and were characterized by SEM and fluorescence microscope. The results demonstrated that the nanofibers electrospun at maximum conditions were straight and that quercetin was distributed throughout the fibers. Finally, the PLGA nanofibrous scaffolds with $1 \mathrm{wt} \%$ of quercetin (PLGA/Q 1) inhibited the proliferation of Staphylococcus aureus (SA) and Klebsiella pneumoniae (KP) bacteria, without any in vitro cell cytotoxicity from the scaffolds. If these results can be confirmed in vivo, the PLGA/Q 1 nanofibrous scaffolds may be applicable for use in total joint arthroplasty particularly due to its effect against multiresistant bacteria. 


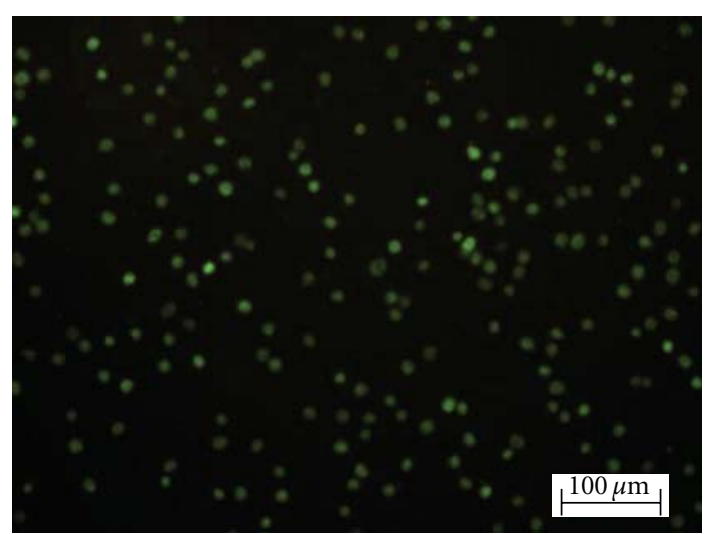

(a)

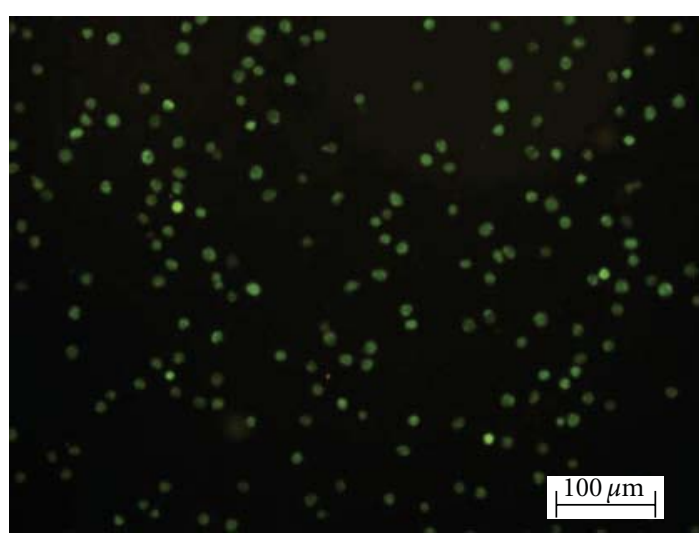

(b)

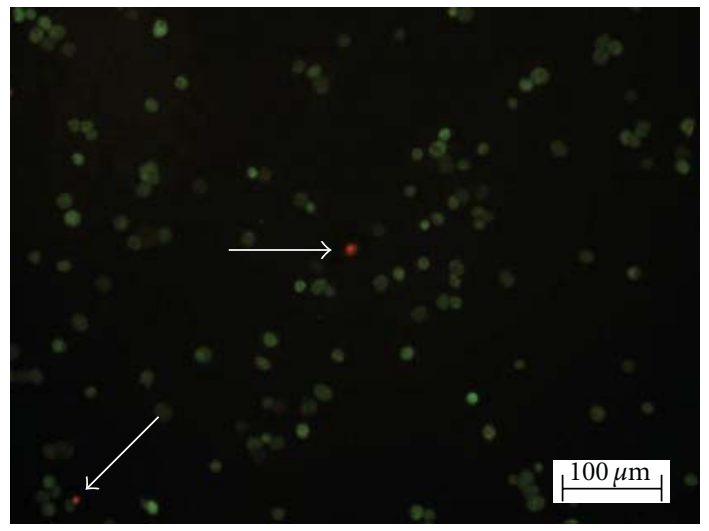

(c)

Figure 8: Fluorescence microscopic images of KB epithelial cells cultured for 7 days on (a) PLGA, (b) PLGA/Q 1, and (c) PLGA/Q 5 nanofibrous scaffolds.

\section{Acknowledgments}

This research was supported by the Research Grants of the Biotechnology development project (2009-0090907) and by the Grant of 2010-0011125 from Ministry of Education, Science and Technology of Korea.

\section{References}

[1] M. R. Peluso, "Flavonoids attenuate cardiovascular disease, inhibit phosphodiesterase, and modulate lipid homeostasis in adipose tissue and liver," Experimental Biology and Medicine, vol. 231, no. 8, pp. 1287-1299, 2006.

[2] L. Bravo, "Polyphenols: chemistry, dietary sources, metabolism, and nutritional significance," Nutrition Reviews, vol. 56, no. 11, pp. 317-333, 1998.

[3] M. G. L. Hertog and P. C. H. Hollman, "Potential health effects of the dietary flavonol quercetin," European Journal of Clinical Nutrition, vol. 50, no. 2, pp. 63-71, 1996.

[4] R. L. Prior, "Fruits and vegetables in the prevention of cellular oxidative damage," American Journal of Clinical Nutrition, vol. 78, supplement 3, pp. 570S-578S, 2003.

[5] M. Alía, R. Mateos, S. Ramos, E. Lecumberri, L. Bravo, and L. Goya, "Influence of quercetin and rutin on growth and antioxidant defense system of a human hepatoma cell line (HepG2)," European Journal of Nutrition, vol. 45, no. 1, pp. 19-28, 2006.
[6] J. P. Brown, "A review of the genetic effects of naturally occurring flavonoids, anthraquinones and related compounds," Mutation Research, vol. 75, no. 3, pp. 243-277, 1980.

[7] M. A. Read, "Flavonoids: naturally occurring anti-inflammatory agents," American Journal of Pathology, vol. 147, no. 2, pp. 235-237, 1995.

[8] K. Kuriyama, T. Kitamura, R. Yokoi et al., "Evaluation of testicular toxicity and sperm morphology in rats treated with methyl methanesulphonate (MMS)," Journal of Reproduction and Development, vol. 51, no. 5, pp. 657-667, 2005.

[9] Y. L. Mi and C. Q. Zhang, "Protective effect of quercetin on aroclor 1254-induced oxidative damage in cultured chicken spermatogonial cells," Toxicological Sciences, vol. 88, no. 2, pp. 545-550, 2005.

[10] U. Kaindl, I. Eyberg, N. Rohr-Udilova, C. Heinzle, and B. Marian, "The dietary antioxidants resveratrol and quercetin protect cells from exogenous pro-oxidative damage," Food and Chemical Toxicology, vol. 46, no. 4, pp. 1320-1326, 2008.

[11] S. H. Lee, B. S. Kim, S. H. Kim et al., "Elastic biodegradable poly(glycolide-co-caprolactone) scaffold for tissue engineering," Journal of Biomedical Materials Research A, vol. 66, no. 1, pp. 29-37, 2003.

[12] Z. Ma, M. Kotaki, T. Yong, W. He, and S. Ramakrishna, "Surface engineering of electrospun polyethylene terephthalate (PET) nanofibers towards development of a new material for blood vessel engineering," Biomaterials, vol. 26, no. 15, pp. 2527-2536, 2005. 
[13] J. Venugopal and S. Ramakrishna, "Biocompatible nanofiber matrices for the engineering of a dermal substitute for skin regeneration," Tissue Engineering, vol. 11, no. 5-6, pp. 847854, 2005.

[14] M. S. Khil, D. I. Cha, H. Y. Kim, I. S. Kim, and N. Bhattarai, "Electrospun nanofibrous polyurethane membrane as wound dressing," Journal of Biomedical Materials Research B, vol. 67, no. 2, pp. 675-679, 2003.

[15] X. Wang, I. C. Um, D. Fang, A. Okamoto, B. S. Hsiao, and B. $\mathrm{Chu}$, "Formation of water-resistant hyaluronic acid nanofibers by blowing-assisted electro-spinning and non-toxic post treatments," Polymer, vol. 46, no. 13, pp. 4853-4867, 2005.

[16] I. C. Um, D. Fang, B. S. Hsiao, A. Okamoto, and B. Chu, "Electro-spinning and electro-blowing of hyaluronic acid," Biomacromolecules, vol. 5, no. 4, pp. 1428-1436, 2004.

[17] K. Fujihara, M. Kotaki, and S. Ramakrishna, "Guided bone regeneration membrane made of polycaprolactone/calcium carbonate composite nano-fibers," Biomaterials, vol. 26, no. 19, pp. 4139-4147, 2005.

[18] H. Yoshimoto, Y. M. Shin, H. Terai, and J. P. Vacanti, "A biodegradable nanofiber scaffold by electrospinning and its potential for bone tissue engineering," Biomaterials, vol. 24, no. 12, pp. 2077-2082, 2003.

[19] F. Yang, R. Murugan, S. Ramakrishna, X. Wang, Y. X. Ma, and S. Wang, "Fabrication of nano-structured porous PLLA scaffold intended for nerve tissue engineering," Biomaterials, vol. 25, no. 10, pp. 1891-1900, 2004.

[20] C. M. Agrawal and R. B. Ray, "Biodegradable polymeric scaffolds for musculoskeletal tissue engineering," Journal of Biomedical Materials Research A, vol. 55, no. 2, pp. 141-150, 2001.

[21] E. Behravesh, A. W. Yasko, P. S. Engel, and A. G. Mikos, "Synthetic biodegradable polymers for orthopaedic applications," Clinical Orthopaedics and Related Research, supplement 367, pp. S118-S125, 1999.

[22] K. A. Athanasiou, G. G. Niederauer, and C. M. Agrawal, "Sterilization, toxicity, biocompatibility and clinical applications of polylactic acid/polyglycolic acid copolymers," Biomaterials, vol. 17, no. 2, pp. 93-102, 1996.

[23] J. B. Lee, S. E. Kim, D. N. Heo, I. K. Kwon, and B. J. Choi, "In vitro characterization of nanofibrous PLGA/ gelatin/hydroxyapatite composite for bone tissue engineering," Macromolecular Research, vol. 18, no. 12, pp. 1195-1202, 2010.

[24] T. A. Telemeco, C. Ayres, G. L. Bowlin et al., "Regulation of cellular infiltration into tissue engineering scaffolds composed of submicron diameter fibrils produced by electrospinning," Acta Biomaterialia, vol. 1, no. 4, pp. 377-385, 2005.

[25] M. J. Mondrinos, S. Koutzaki, E. Jiwanmall et al., "Engineering three-dimensional pulmonary tissue constructs," Tissue Engineering, vol. 12, no. 4, pp. 717-728, 2006.

[26] H. J. Shin, C. H. Lee, I. H. Cho et al., "Electrospun PLGA nanofiber scaffolds for articular cartilage reconstruction: mechanical stability, degradation and cellular responses under mechanical stimulation in vitro," Journal of Biomaterials Science, Polymer Edition, vol. 17, no. 1-2, pp. 103-119, 2006.

[27] Z. C. Xing, W. P. Chae, M. W. Huh et al., "In vitro antibacterial and cytotoxic properties of silver-containing poly $(\mathrm{L}-$ lactide-co-glycolide) nanofibrous scaffolds," Journal of Nanoscience and Nanotechnology, vol. 11, no. 1, pp. 61-65, 2011.

[28] K. H. Lee, H. Y. Kim, Y. J. Ryu, K. W. Kim, and S. W. Choi, "Mechanical behavior of electrospun fiber mats of poly(vinyl chloride)/polyurethane polyblends," Journal of Polymer Science $B$, vol. 41, no. 11, pp. 1256-1262, 2003.
[29] A. Alhadlaq, J. H. Elisseeff, L. Hong et al., "Adult stem cell driven genesis of human-shaped articular condyle," Annals of Biomedical Engineering, vol. 32, no. 7, pp. 911-923, 2004.

[30] T. P. T. Cushnie and A. J. Lamb, "Antimicrobial activity of flavonoids," International Journal of Antimicrobial Agents, vol. 26, no. 5, pp. 343-356, 2005.

[31] M. Lipkin, B. Reddy, H. Newmark, and S. A. Lamprecht, "Dietary factors in human colorectal cancer," Annual Review of Nutrition, vol. 19, pp. 545-586, 1999.

[32] G. G. Duthie, S. J. Duthie, and J. A. M. Kyle, "Plant polyphenols in cancer and heart disease: implications as nutritional antioxidants," Nutrition Research Reviews, vol. 13, no. 1, pp. 79-106, 2000.

[33] G. Agullo, L. Gamet, C. Besson, C. Demigne, and C. Remesy, "Quercetin exerts a preferential cytotoxic effect on active dividing colon carcinoma HT29 and Caco-2 cells," Cancer Letters, vol. 87, no. 1, pp. 55-63, 1994.

[34] F. O. Ranelletti, R. Ricci, L. M. Larocca et al., "Growthinhibitory effect of quercetin and presence of type-II estrogenbinding sites in human colon-cancer cell lines and primary colorectal tumors," International Journal of Cancer, vol. 50, no. 3, pp. 486-492, 1992.

[35] M. Richter, R. Ebermann, and B. Marian, "Quercetin-induced apoptosis in colorectal tumor cells: possible role of EGF receptor signaling," Nutrition and Cancer, vol. 34, no. 1, pp. 88-99, 1999.

[36] R. L. Singhal, Y. Albert Yeh, N. Prajda, E. Olah, G. W. Sledge, and G. Weber, "Quercetin down-regulates signal transduction in human breast carcinoma cells," Biochemical and Biophysical Research Communications, vol. 208, no. 1, pp. 425-431, 1995.

[37] G. Scambia, F. O. Ranelletti, P. B. Panici et al., "Quercetin potentiates the effect of adriamycin in a multidrug-resistant MCF-7 human breast-cancer cell line: p-glycoprotein as a possible target," Cancer Chemotherapy and Pharmacology, vol. 34, no. 6, pp. 459-464, 1994.

[38] T. B. Kang and N. C. Liang, "Studies on the inhibitory effects of quercetin on the HL-60 leukemia cells," Biochemical Pharmacology, vol. 54, no. 9, pp. 1013-1018, 1997.

[39] S. Uddin and M. A. Choudhry, "Quercetin, a bioflavonoid, inhibits the DNA synthesis of human leukemia cells," Biochemistry and Molecular Biology International, vol. 36, no. 3, pp. 545-550, 1995.

[40] S. M. Kuo, "Antiproliferative potency of structurally distinct dietary flavonoids on human colon cancer cells," Cancer Letters, vol. 110, no. 1-2, pp. 41-48, 1996.

[41] C. W. Chi, Y. F. Chang, Y. R. Ou et al., "Effect of quercetin on the in vitro and in vivo growth of mouse hepatoma cells," Oncology Reports, vol. 4, no. 5, pp. 1021-1024, 1997.

[42] A. Robaszkiewicz, A. Balcerczyk, and G. Bartosz, "Antioxidative and prooxidative effects of quercetin on A549 cells," Cell Biology International, vol. 31, no. 10, pp. 1245-1250, 2007. 

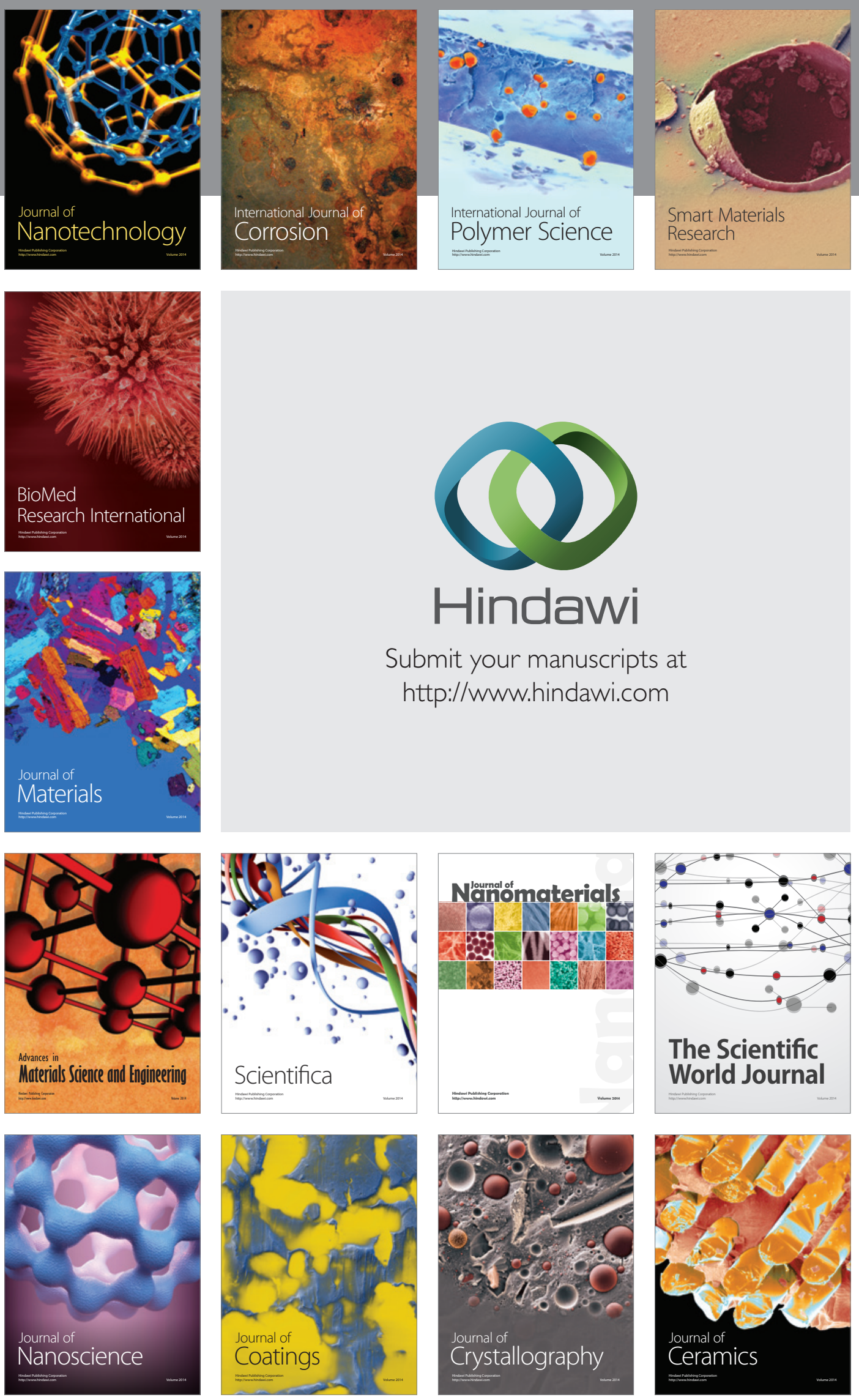

The Scientific World Journal

Submit your manuscripts at

http://www.hindawi.com

\section{World Journal}

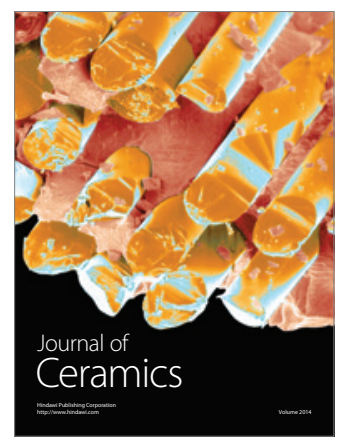

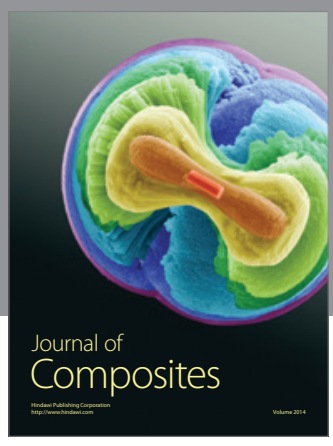
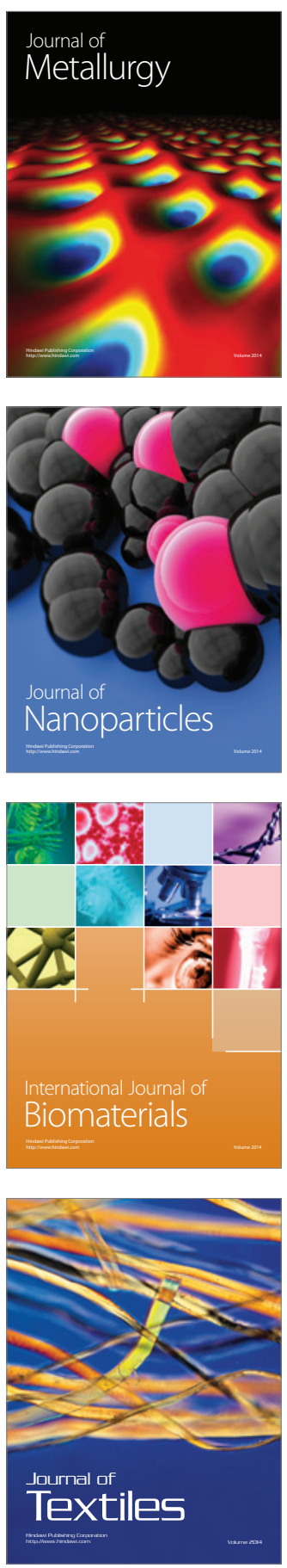